\title{
A leitura no contexto da educação pré-escolar'
}

\author{
Reading in Preschool (Kindergarten) Education
}

\author{
ÂNGELA BALÇA \\ EVA LEAL \\ Universidade de Évora \\ Portugal \\ apb@uevora.pt \\ evita_leal@hotmail.com
}

(Recibido o6-O3-20I4; aceptado $\left.12-05^{-2 O I} 4\right)$

Resumo. Este texto decorre do estudo realizado no âmbito do Mestrado em Ciências da Educação - Supervisão Pedagógica, concluído numa instituição de ensino superior portuguesa, e centra-se nas questões da literacia emergente em contexto de jardim-de-infância. Dada a relevância desta problemática, interrogámonos sobre a forma como os educadores de infância cooperantes e os estagiários conseguem (ou não), por meio de interações e práticas de leitura, aproximar as crianças do livro e da literatura infantil, promovendo a formação de leitores precoces. Sendo assim, seguimos a metodologia do estudo de caso para mostrarmos a realidade de três contextos de supervisão $(A, B$ e $C)$ no domínio da abordagem à leitura. Nas conclusões, é evidente que o par pedagógico $C$ se destaca na promoção de um ambiente literácito quantitativa e qualitativamente rico de experiências significativas, refletindo um investimento sério e constante na promoção da leitura e da escrita.

Palavras-chave: Leitura; literacia emergente; jardim-de-infância; formação de leitores; supervisão.
Abstract.This text results from the study in the scope of the Masters Degree in Educational Sciences - Pedagogical Supervision completed at a Portuguese University, and focuses on issues of early literacy in the kindergarten context. Given the importance of this problem, we sought to understand the way cooperating kindergarten school teacher and trainees can (or not) through interactions and reading practices, bring children's books, children's literature and children closer, by promoting the formation of early readers. Thus, we followed a case study methodology in order to show the reality of three contexts of supervision ( $A, B$ and $C$ ) concerning the approach to reading. According to the conclusions, it is clear that teaching pair $C$ stands out in promoting a quantitatively and qualitatively rich environment regarding significant literacy experiences and reflecting a serious and steady investment in the promotion of reading and writing.

Keywords: Reading; early literacy; kindergarten; reader development; supervision

\footnotetext{
${ }^{\text {I }}$ Para citar este artículo: Balça, Ângela y Leal, Eva (20I4). A leitura no contexto da educação pré-escolar. Álabe 10. [www.revistaalabe.com]

DOI IO.I5645/Alabe.20I4.IO.5
} 


\section{I - Introdução}

Este texto decorre do estudo realizado no âmbito do Mestrado em Ciências da Educação - Supervisão Pedagógica, concluído numa instituição de ensino superior portuguesa, e centra-se em preocupações que acompanham a vida diária de muitos educadores de infância, nomeadamente as relacionadas com as questões da literacia emergente. A educação pré-escolar é uma etapa decisiva na vida das crianças e, conforme refere SimSim (2008) em Mata (2008: 7), "configura-se como um espaço de tempo privilegiado para aprendizagens estruturantes e decisivas no desenvolvimento da criança." Neste sentido,

é importante que se ofereça uma educação pré-escolar de qualidade, no que diz respeito à abordagem da leitura e da escrita, para que as crianças possam atingir, no futuro, o sucesso educativo e o bem-estar social, tendo o educador um papel determinante neste processo. (Fernandes (2003) citado em Moniz (2009: 23))

Além de sensibilizar para o prazer da leitura, o educador de infância pode despertar a criança para a importância e funções da leitura, integrando todas as áreas de conteúdo de forma articulada e lúdica, facilitando este profissional a emergência de comportamentos leitores. Para tal, os educadores de infância necessitam investir no ambiente educativo, dotando-o de livros infantis diversificados e outros materiais impressos de fácil acesso às crianças.

Dada a relevância desta problemática, interrogámo-nos sobre a forma como os educadores de infância cooperantes e os estagiários conseguem (ou não), por meio de interações e práticas de leitura, aproximar as crianças do livro e da literatura infantil, promovendo a formação de leitores precoces. Sendo assim, este estudo visa mostrar a realidade de três contextos de supervisão (A, B e C) no domínio da abordagem à leitura. Neste artigo, para além de revermos alguns estudos nesta área, analisamos e discutimos os dados da nossa investigação e apresentamos as respetivas conclusões.

\section{2 - O educador de infância enquanto mediador do processo de promoção da leitura}

Parece hoje ser consensual na literatura da especialidade que o contacto com o livro e com a leitura/escrita pode começar desde as idades mais precoces. Porém, nestas faixas etárias, o papel do adulto, do adulto mediador, seja ele o educador de infância ou algum membro da família, é indispensável. E afigura-se-nos que o papel desempenhado pelo adulto mediador, no contacto e na interação da criança com o livro, ainda não está completamente interiorizado pelos diversos atores educativos. Azevedo (20o6) e Cerrillo (2006) afirmam a importância do adulto mediador, cujo papel passa por selecionar e adquirir os textos que as crianças vão ouvir ler e vão contactar bem como proporcionarlhes a hipótese de dialogar com o texto, sempre no sentido do desenvolvimento da compreensão leitora. Assim, Cerrillo (2006: 36) afirma que "Na literatura infantil, o media- 
dor é, quase sempre, o primeiro receptor da obra, que facilitará ideias e caminhos para realizar leituras, e também para as escolher, porque o destinatário da mesma é ainda um ser em desenvolvimento."

Conforme referem Tussi e Rösing (2009), o mediador deve "ensinar pelo exemplo", demonstrando uma boa relação com os livros, prazer na leitura e tendo formação sobre o tema. Só um profissional com total sensibilidade e conhecimento sobre as questões de leitura consegue fazê-la chegar às crianças de forma lúdica e cativante, envolvendo-as e motivando-as intrinsecamente a querer ouvir o que vai ser lido.

A este respeito Fernandes (2005: IO) diz que o educador deve assumir-se perante o grupo como um "modelo de actos literácitos: lendo, escrevendo, pensando e demonstrando prazer com tudo isto."

Mata (2008) também realça a importância das atitudes e sentimentos de quem medeia as interações da criança com os livros e com a leitura. Através das interações partilhadas de leitura, o mediador consegue transmitir à criança o prazer e satisfação que retira do momento de exploração dos livros.

Essa atitude positiva face à leitura vai ajudar a motivar a criança a querer aprender a ler, observar o mediador em leituras possibilita-lhe aprender "comportamentos de leitor" na medida em que se vai apropriando de comportamentos caraterísticos de um leitor e mais tarde, perante um livro, reproduz esses mesmos comportamentos (Mata, 2008).

Mata (2008: 79) afirma ainda que "a forma como se lê ou conta uma história, tal como toda a exploração que a antecede ou lhe dá continuidade, são elementos importantes para o desenvolvimento da curiosidade e do interesse pelos livros e a leitura."

De acordo com Cerrillo (2006), ninguém recusa que a prática da leitura precoce traz benefícios à criança, ao nível do desenvolvimento de competências de leitura e ao nível do desenvolvimento pessoal, permitindo-lhe compreender o mundo e as suas transformações, facultando-lhe instrumentos para a crítica e a capacidade de comunicar com os outros em diversos contextos. $\mathrm{O}$ autor acima mencionado refere " $\mathrm{O}$ leitor não nasce, faz-se: mas o não leitor também (...)"(Cerrillo, 2006:35), tudo depende das experiências leitoras motivadoras ou não que geralmente acontecem em dois contextos: o familiar e o educativo.

A diversidade de interações caraterísticas do contexto educativo permite alargar a vertente social da leitura. Segundo Mata (2008), em idade pré-escolar, a leitura não é um ato solitário, como as crianças não sabem ler, necessitam de alguém que lhes leia. Essa interação entre educadora de infância e crianças permite trocar ideias e partilhar opiniões alargando a vertente social da leitura. A partilha típica desses momentos de leitura, no contexto educativo, permite às crianças envolver-se na leitura e confrontar-se com gostos diferentes dos seus, conhecer realidades diversas da sua desfrutando e explorando livros novos e outros suportes de leitura.

De acordo com as Orientações Curriculares para a Educação Pré-Escolar (2002) é essencial em educação pré-escolar a diversidade de livros infantis, de modo a que as crianças contatem com diversos textos: em prosa e poesia; mas também com livros com 
outro tipo de conteúdo: enciclopédias, dicionários, permitindo-lhes aumentar o conhecimento sobre esses suportes e facilitando a apropriação das funções da leitura. Nesta perspetiva o referido documento enuncia que "O gosto e interesse pelo livro e pela palavra escrita inicia-se na educação pré-escolar.", afirmando-se ainda que "O contato e frequência de bibliotecas pode também começar nesta idade, se as crianças tiverem oportunidade de utilizar, explorar e compreender a necessidade de as consultar e de as utilizar como espaços de recreio e de cultura." (Orientações Curriculares para a Educação Pré-Escolar, 2OO2: 72 ).

Assim, chama-se a atenção dos educadores para a importância de proporcionar às crianças momentos de fruição de livros em espaços próprios, as bibliotecas; sejam as bibliotecas públicas ou as bibliotecas da própria sala ou da instituição de educação pré-escolar. Fernandes (2005) refere que as bibliotecas devem compreender crianças e adultos em leituras partilhadas, e mais do que um refúgio para a agitação positiva de uma sala ou um espaço onde os livros descansam e não se estragam, a biblioteca deve ser um espaço de descoberta e aprendizagem.

Todas estas ações e práticas, imbuídas de intencionalidade educativa, com sentido para as crianças e mediadas pelo adulto contribuem para a construção do projeto pessoal de leitor dos mais novos. O desejo de aprender a ler, a compreensão da funcionalidade da linguagem escrita, o conhecimento de algumas regras do impresso e da natureza da linguagem escrita concorrem para que à chegada ao I. ${ }^{\circ}$ ciclo haja uma entrada, certamente mais motivadora, na aprendizagem formal da leitura e da escrita. A formação do leitor continua com a promoção diária da hora do conto e com o contacto frequente com todos os tipos de texto, com especial relevância para o texto de literatura para a infância.

\section{3-Metodologia}

No presente estudo, o problema a investigar está intimamente ligado à necessidade de se conhecer o trabalho dos educadores de infância cooperantes, junto dos estagiários, relativamente à abordagem à leitura na educação pré-escolar. Concretamente, pretendemos compreender como os educadores de infância cooperantes e os estagiários, por meio de interações e práticas de leitura, conseguem aproximar as crianças do livro e da literatura infantil, contribuindo para criar hábitos de leitura precoces.

Na tentativa de responder ao problema da investigação, definimos os seguintes objetivos específicos:

- Relacionar a formação inicial e contínua, no âmbito da abordagem à leitura, com as práticas pedagógicas dos educadores de infância cooperantes e dos estagiários.

- Compreender as conceções pedagógicas dos educadores de infância cooperantes e dos estagiários sobre a utilização dos livros infantis na abordagem à leitura.

- Caraterizar o papel do educador de infância cooperante como orientador do estagiário na promoção hábitos de leitura em contexto pré-escolar. 
Atendendo a estes objetivos, partimos em busca das respostas aos seguintes pontos:

I) formação profissional e pessoal

2) conceções de leitura

3) planificação da prática pedagógica

4) supervisão da prática pedagógica.

Neste estudo, seguimos a metodologia do estudo de caso que, de acordo com Merriam (I988), "consiste na observação detalhada de um contexto, ou indivíduo, de uma única fonte de documentos ou de um acontecimento específico." (Merriam (I988) citado em Bogdan \& Bicklen, (1994:89)). Entendemos assim, o estudo caso, como uma metodologia, que nos permite aprofundar o conhecimento sobre a realidade que nos propomos a investigar, neste caso em particular, as conceções pedagógicas quanto ao uso dos livros infantis, no domínio da leitura, em três contextos de supervisão na educação pré-escolar. Arnal, Rincón e Latorre (I992) acrescentam “El estúdio de casos es un diseño de investigación particularmente apropriado para estudiar un caso o situación com cierta intensidade en um período de tiempo corto" (Arnal, Rincón e Latorre (r992: 206)). Assim, a metodologia do estudo de caso pareceu-nos ser adequada ao nosso estudo, uma vez que a recolha de dados só podia ser realizada durante o período de desenvolvimento integral das práticas pedagógicas das estagiárias.

A nossa amostra é constituída por três educadoras de infância cooperantes e três estagiárias de uma instituição de ensino superior. Num dos jardins-de-infância trabalhámos com os pares A e B, na outra instituição trabalhámos com o par C.

A recolha de dados neste estudo foi realizada com base em dois instrumentos, o inquérito por entrevista a cada participante e a observação direta em cada um dos três contextos de supervisão. Considerámos que estes instrumentos são adequados ao objetivo traçado e em simultâneo conferem mais fiabilidade aos dados obtidos, uma vez que se trata de duas fontes distintas de informação. Assim sendo, realizámos as entrevistas e três observações diretas, uma em cada contexto de supervisão (par A, par B e par C).

\section{4- O estudo: análise, discussão de resultados e conclusões}

Neste ponto, apresentamos e discutimos os dados do nosso estudo, relembrando os objetivos e destacando alguns resultados que nos ajudaram a retirar diversas ilações. Neste estudo acompanhámos três pares pedagógicos. Relativamente ao par A, a educadora de infância tinha treze anos de serviço e a estagiária frequentava o Mestrado em Educação Pré-Escolar; no par B, a educadora de infância possuía quinze anos de serviço e a estagiária frequentava o Mestrado em Educação Pré-Escolar; e, por fim, no par C, a educadora de infância tinha também quinze anos de serviço e a estagiária frequentava o Mestrado em Educação Pré-Escolar e Ensino do I. ${ }^{\circ}$ Ciclo do Ensino Básico. 
No que diz respeito ao primeiro objetivo - Relacionar a formação inicial e contínua, no âmbito da abordagem à leitura, com as práticas pedagógicas dos educadores de infância cooperantes e dos estagiários - foi do nosso interesse conhecer o processo curricular académico das educadoras de infância cooperantes e das estagiárias no âmbito da leitura em educação pré-escolar. Então pudemos verificar que todas as entrevistadas, na sua formação inicial, frequentaram unidades curriculares relacionadas com a leitura e literatura infantil. É importante sublinhar que as estagiárias B e C, ao serem questionadas, não se limitaram a responder acerca das unidades curriculares frequentadas no curso, mas acrescentaram o impacto que teve para si frequentarem essas unidades curriculares. Ambas as estagiárias consideram que os conteúdos lecionados nas unidades curriculares foram de extrema importância e sobretudo esclarecedores, não só porque as instruíram teoricamente sobre o tema, mas também porque as prepararam através de exemplos concretos de atividades e da recomendação de materiais, nomeadamente livros infantis. Este contributo foi fundamental para melhorarem o seu desempenho na promoção de atividades de leitura, durante o estágio curricular no contexto da educação pré-escolar, proporcionando momentos de qualidade às crianças. Em relação à formação contínua, verificámos que as três educadoras de infância cooperantes, em determinados momentos das suas vidas, investiram na sua formação contínua, complementando conhecimentos ao nível da abordagem à leitura na educação pré-escolar. De facto, as três educadoras de infância cooperantes referem ter aderido a formações sobre o tema da leitura e da escrita, promovidas pelo Movimento da Escola Moderna (MEM). Inclusivamente, a educadora de infância do par C assumiu o papel de dinamizadora em algumas sessões sobre leitura e escrita, no MEM, o que pressupõe que a sua prática tenha caraterísticas interessantes nesse âmbito que podem ser partilhadas com outros profissionais. De referir ainda que, em relação aos modelos curriculares para a educação pré-escolar, duas das educadoras de infância cooperantes (pares B e C) apenas tinham tomado contacto com eles na sua formação contínua.

Também quisemos perceber quais eram os hábitos de leitura pessoais das educadoras de infância cooperantes e das estagiárias entrevistadas e apurámos que todas gostam de ler, mas não são leitoras regulares, alegando essencialmente a falta de tempo. As educadoras de infância cooperantes são absorvidas pela rotina do dia-a-dia e às estagiárias impõem-se leituras no âmbito da formação inicial. Este aspeto é comprovado especialmente pelos testemunhos das três estagiárias, que estando em processo formativo dão prioridade às leituras instrumentais, deixando de lado a leitura por prazer, por enriquecimento pessoal (Cerrillo, 2006). Como refere Azevedo (2006) “(...) é imperioso que os mediadores de leitura (...) sejam eles próprios bons leitores, que não apenas gostem de ler, como leiam regularmente, exercitando essa actividade cultural com intensidade e qualidade." (Azevedo (2006: 27). Contudo, percebemos que embora as educadoras de infância cooperantes e as estagiárias não tenham hábitos pessoais de leitura regulares, no contexto de sala, leem para as crianças com frequência o que é evidenciado na literatura sobre o tema como sendo fundamental na formação dos mais novos. De um modo 
geral, os três pares de supervisão referiram desenvolver atividades de leitura com diversas intenções: promover o interesse e gosto pelos livros; desenvolver a linguagem oral; conhecer o código escrito, assim como algumas das suas regras; criar hábitos de leitura; interiorizar regras de respeito pelo grupo, nomeadamente as necessárias para a prática da leitura; estimular a imaginação e a curiosidade; promover o conhecimento do mundo e da sociedade. Intenções estas que são corroboradas, entre outros, por Mata (2008) e indicam que as entrevistadas possuem conhecimentos sobre o tema, assim como têm objetivos bem definidos neste âmbito para atingir com as crianças, o que nos faz levantar a hipótese desses conhecimentos terem sido proporcionados pelas unidades curriculares no domínio da leitura e literatura infantil, durante a sua formação inicial e contínua.

Relativamente ao segundo objetivo - Compreender as conceções pedagógicas dos educadores de infância cooperantes e dos estagiários sobre a utilização dos livros infantis na abordagem à leitura - podemos dizer que os três pares de supervisão estão de comum acordo quando afirmam que as crianças podem iniciar o contato com os livros infantis e a leitura durante o primeiro ano de vida e quando revelam não ter dúvidas de que a criança, quando vai para a educação pré-escolar, já leva um conjunto de conhecimentos sobre leitura adquiridos em casa ou na creche. Tal como afirma Cerrillo (2006):

(...) fazemo-nos leitores ou não leitores com o passar do tempo, no decorrer de um processo formativo no qual intervém o desenvolvimento da personalidade, e no qual vivenciamos experiências leitoras motivadoras e desmotivadoras, quase sempre em dois únicos contextos, o familiar e o escolar. (Cerrillo, 2006: 35)

Do mesmo modo, todos os pares partilham a mesma ideia quanto às vantagens da utilização do livro para promover hábitos de leitura, considerando-o um instrumento de trabalho essencial, enquanto fonte de conhecimento e de prazer. As educadoras de infância cooperantes e as estagiárias valorizam portanto a aquisição de competências do leitor na primeira infância e fazem-no conscientes de que será um fator decisivo na sua adaptação ao I. ${ }^{\circ}$ ano do I. ${ }^{\circ}$ ciclo do ensino básico e, consequentemente, no sucesso durante o seu percurso escolar. Porém as entrevistadas não se pronunciam sobre as questões que se prendem com o desenvolvimento global das crianças, no aspeto social e de cidadania. Aparentemente, as entrevistadas não pensam nessa perspetiva a longo prazo. Não pensam que as competências do leitor e os conhecimentos de literacia que as crianças adquirem na educação pré-escolar lhes permitem não só ler livros para ter sucesso no I. ${ }^{\circ}$ ciclo, mas ler o mundo, ler a sociedade onde vivem e permitem-lhes tornar-se livres e autónomas no ato da cidadania.

Nos três contextos (A, B, C), confirmámos ainda a possibilidade de existir uma relação entre as conceções das entrevistadas e a sua ação educativa. Embora as atividades desenvolvidas nos três contextos refletissem um grande investimento na promoção da leitura, o contexto educativo do par C destacou-se por ser recheado de leitura e escrita. Temos exemplos concretos - a partir de um livro, o par C criou condições (jogos para descobrir letras, jogos para descobrir palavras, entre outros) para que existisse leitura 
no verdadeiro sentido da palavra; ia à biblioteca pública para pesquisar ou só para ouvir histórias novas; organizou a biblioteca da sala, que era considerada o centro de recursos para enriquecer atividades noutras áreas. São, efetivamente, caraterísticas de um trabalho que reflete uma intencionalidade no âmbito da aquisição de competências que certamente facilitarão a aprendizagem formal da leitura no I. ${ }^{\circ}$ ciclo. Há portanto aqui um distanciamento dos pares A e B, que embora demonstrem promover atividades de leitura e desenvolver competências linguísticas nas crianças, não é seu objetivo antecipar o ensino-aprendizagem da leitura, porque consideram-no uma caraterística do I. ${ }^{0}$ ciclo. Contudo, outro fator que poderá justificar esta diferença nos procedimentos, prende-se com o facto de o par C ser o único que implementa integralmente um modelo curricular, seguindo rigorosamente os dias das saídas ao exterior, os dias para trabalho de texto, para a hora do conto e a organização do espaço, dos materiais e do grupo. Isto não acontece nos contextos dos pares A e B, que muito embora tenham referido aplicar o mesmo modelo curricular, não o seguiam à risca, pois demonstraram mais flexibilidade para alterar a hora do conto, iam com menos frequência a bibliotecas ou livrarias e não tinham um dia definido para realizar trabalho de texto. Estes dois pares alegaram ter alguns momentos de leitura por prazer, mas geralmente os livros eram utilizados de modo transversal, isto é, como meio para chegar a outras áreas (fazer pintura à vista, confecionar alimentos, resolver situações problema, entre outros), não se centrando tantas vezes na exploração do texto infantil quanto o par $\mathrm{C}$, que trabalhava com a intenção de transmitir às crianças um sentido crítico para distinguirem um bom livro de um livro menos bom (por vezes liam livros com o mesmo tema e comparavam para ver se faltavam partes importantes da história).

Outro fator de diferenciação da prática pedagógica entre os três pares de supervisão está intimamente ligado à organização do espaço para as atividades de leitura, concretamente a organização da biblioteca da sala. Destacamos, pela negativa, o par B, que além de não ter criado um ambiente acolhedor nesse espaço, também não investiu na qualidade, quantidade e diversidade de materiais que estavam à disposição das crianças, aspeto referido pela estagiária e confirmado por nós no dia da observação direta. O par A criou um ambiente agradável e convidativo, com acesso a vários livros, aproximando-se mais da realidade do par C, que de acordo com a literatura é a ideal para uma sala. Realçamos a quantidade, qualidade e diversidade dos livros infantis que estavam sempre ao alcance das crianças, organizados por temas e etiquetados, sendo esta biblioteca considerada pelas crianças e adultos um centro de recursos para diversas atividades durante todo o dia.

Quanto aos critérios privilegiados na escolha de livros infantis, os três pares destacaram os gostos e interesses das crianças (pares A, B e C), os temas dos trabalhos de projeto (pares A, B e C), as ilustrações (pares A, B e C), o texto (pares B e C), os autores (par C), o nível de desenvolvimento e competências adquiridas (par B), o Plano Nacional de Leitura Ler + (par A), as situações problema (par A) e a faixa etária (par A). 
No que concerne ao terceiro e último objetivo: Caraterizar o papel do educador de infância cooperante como orientador do estagiário na promoção de hábitos de leitura em contexto pré-escolar - percebemos que as três educadoras de infância cooperantes estabeleceram uma relação de confiança com as estagiárias, partilhando com elas estratégias e orientações que lhes permitiram melhorar o seu desempenho perante situações imprevistas ou dificuldades sentidas. No geral, as estagiárias indicaram que foi criada uma interação muito positiva com as educadoras de infância cooperantes, pois estas valorizavam o trabalho realizado, faziam diversas sugestões, ajudavam na resolução de problemas, planificavam conjuntamente as atividades e fundamentavam as suas opções quanto à escolha do material e das propostas de atividades de promoção de leitura, discutindo os objetivos que pretendiam alcançar com as crianças.

Quanto ao contributo das educadoras de infância cooperantes na orientação de atividades de leitura junto das estagiárias, notámos que estas eram despertas para a abordagem à leitura e que conduziam várias atividades nesse âmbito, no entanto verificámos que as estagiárias também eram bastante sensíveis ao tema influenciando-se mutuamente. Sabemos que existia com regularidade partilha de livros de histórias e incentivo para a utilização de livros de pesquisa nos três contextos. Relativamente ao hábito de frequentar espaços de biblioteca com as crianças, constatamos que o par C organizava com mais frequência atividades nesses espaços do que os pares A e B.

No que concerne à perspetiva sobre as práticas de promoção de leitura do parceiro, as educadoras de infância cooperantes indicaram que as estagiárias eram promotoras de atividades de leitura, assim como as estagiárias dos pares A e C referiram que as educadoras de infância organizavam com regularidade atividades de leitura e, em particular a estagiária do par C, referiu considerar a educadora um exemplo a seguir, um modelo de atos literácitos (Fernandes, 2005). Inversamente, a estagiária do par B deixou transparecer alguns indicadores, ao longo da conversa, que nos induziram para a possibilidade desta considerar que a educadora de infância cooperante podia investir mais nos materiais e nas atividades de promoção de leitura.

Relativamente ao acompanhamento do trabalho no processo de supervisão, verificámos que para os pares A e B era habitual reunir à sexta-feira para a auto e hetero reflexão e que para o par $\mathrm{C}$ o acompanhamento era imediato às situações em vez de ter um dia marcado. Assim sendo, podemos dizer que nos três contextos existia um trabalho de acompanhamento permanente às estagiárias.

Desta análise e discussão de dados evidencia-se o trabalho desenvolvido pelo par C. Este par implementava de forma coerente e sistemática um modelo pedagógico na sua ação educativa (neste caso o MEM); realizava diversas atividades específicas no domínio da leitura e da escrita; a biblioteca da sala do par C tinha uma maior quantidade e diversidade de livros de qualidade ao alcance das crianças; havia um dia fixo para a realização da Hora do Conto e para a atividade de trabalho de texto; este par tinha uma atitude mais dinâmica quer na exploração da biblioteca da sala quer da biblioteca pública. O par C 
destaca-se ainda por o seu ambiente educativo estar repleto de leitura e de escrita, centrando-se a sua ação mais vezes na exploração do livro infantil.

\section{5-Considerações Finais}

Este estudo assumiu uma importância basilar na nossa própria formação e desenvolvimento, na medida em que nos permitiu aprofundar conhecimentos no âmbito da abordagem à leitura na educação pré-escolar e, simultaneamente, no domínio da supervisão pedagógica. Permitiu-nos compreender os comportamentos das educadoras de infância cooperantes e das estagiárias face à abordagem precoce de leitura e verificar se estes se mostravam consistentes com as suas conceções. Por outro lado, permitiu-nos conhecer o papel das educadoras de infância cooperantes como orientadoras das estagiárias na promoção de hábitos de leitura junto das crianças.

Os conhecimentos adquiridos a partir desta investigação contribuíram ao longo deste período para refletir e melhorar o desempenho enquanto educadora de infância e também educadora cooperante. Ao conhecer outras realidades, contextos, procedimentos e convicções, conjuntamente com as informações científicas adquiridas através da literatura pesquisada, iniciou-se inevitavelmente um processo de introspeção que também nos permitiu regular a nossa prática pedagógica.

Esperamos que o estudo contribua de igual modo para que outros educadores de infância compreendam o interesse e a importância dos livros e da literatura infantil, na formação integral das crianças, reservando a essas obras um lugar distinto nas suas salas. 


\section{Referências Bibliográficas}

-Arnal, J., Rincón, D., e Latorre, A. (1992). Investigación educativa. Fundamentos y metodologías. Barcelona: Editorial Labor.

-Azevedo, F. (2006). Literatura infantil, recepção leitora e competência literária. In F. Azevedo. Língua materna e literatura infantil (pp. II-32) Lisboa: LIDEL

- Bogdan, R. e Bicklen, S. (I994). Investigação qualitativa em educação - uma introdução à teoria e aos métodos. Porto: Porto Editora.

- Cerrillo, P. (2006). Literatura infantil e mediação leitora. In F. Azevedo. Língua Materna e Literatura infantil. (pp. 33-46) Lisboa: LIDEL

- Fernandes, P. (2005). Literacia emergente e contextos educativos. Cadernos de Educação de Infäncia, 74, 8-II.

- Mata, L. (2008). À descoberta da escrita: textos de apoio para educadores de infáncia. Lisboa: DGIDG - Ministério da Educação.

- Moniz, M. (2009). A abordagem da leitura e da escrita na educação pré-escolar em contexto de supervisão em Angra do Heroísmo. Dissertação de Mestrado em Supervisão Pedagógica. Universidade dos Açores. Obtido em 26/IO/2OII em https://repositorio.uac.pt/bitstream/IO4OO.3/456/I/DissertMestradoMariaMargaridaTevesMoniz.pdf

- Silva, M. I. (Coord.) (2002). Orientações curriculares para a educação pré-escolar. Lisboa: DGIDC - Ministério da Educação.

-Tussi, R. e Rösing, T. (2009). Programa bebelendo - Uma intervenção precoce de leitura. São Paulo: Global Editora. 